\title{
Comprehensive Treatment of a Partially Edentulous Patient with Overdentures
}

\author{
${ }^{1}$ Ganesh Pandurang Mengal, ${ }^{2}$ Sabita M Ram, ${ }^{3}$ Jyoti Nadgere, ${ }^{4}$ Naisargi Shah
}

\begin{abstract}
Treatment of partially edentulous patients with few remaining teeth is very challenging. These cases can be successfully treated with natural teeth supported overdentures. Comprehensive treatment plan with natural teeth supported overdentures saves the proprioceptive response of the teeth, along with other benefits such as improved masticatory efficiency, better retention, stability, support as compared to conventional tissue supported complete dentures. The other most important benefit of overdentures is the psychological security of well retaining dentures which increases patient's confidence level. This article presents a case report in which a partially edentulous patient was successfully rehabilitated with comprehensive treatment of maxillary natural teeth supported overdenture with locator attachment (Zest Anchors) and mandibular partial denture.
\end{abstract}

Keywords: Overdenture, Locator attachment, Preventive prosthodontics.

How to cite this article: Mengal GP, Ram SM, Nadgere J, Shah N. Comprehensive Treatment of a Partially Edentulous Patient with Overdentures. J Contemp Dent 2014;4(3):185-189.

\section{Source of support: Nil}

\section{Conflict of interest: None}

\section{INTRODUCTION}

Preventive prosthodontics emphasizes the importance of any procedure that can delay or eliminate future prosthodontic problems. Natural tooth supported overdentures is one of the best comprehensive treatments available today in preventive prosthodontics. Overdenture treatment is a notion which precluded the inevitability of 'floating plastics' in edentulous mouth. ${ }^{1}$ It has always offered a sensible and prudent appeal for dentists and numerous patients have benefited by it. ${ }^{1}$ The concept of overdenture is far from new. It is almost 150 years back when Ledger (1856) suggested the idea of leaving roots of natural teeth to support a complete denture. ${ }^{2}$

Today, the use of overdenture is one of the most feasible treatment plans available for rehabilitating the

\footnotetext{
${ }^{1}$ Postgraduate Student, ${ }^{2}$ Dean, Professor and Head, ${ }^{3,4}$ Professor

${ }^{1-4}$ Department of Prosthodontics, MGM Dental College and Hospital, Navi Mumbai, Maharashtra, India

Corresponding Author: Ganesh Pandurang Mengal, Postgraduate Student, Department of Prosthodontics, MGM Dental College and Hospital, Navi Mumbai, Maharashtra, India, Phone: 9028546321, e-mail: dr.ganeshmengal@gmail.com
}

partially edentulous patients with very few teeth remaining. It provides better function than conventional tissue supported complete denture through a variety of parameters, such as improved masticatory efficiency, preservation of proprioceptive response, better stability, support, retention, and less trauma to the supporting tissues. ${ }^{1,3}$ The other most important benefit of overdentures is the psychological security of well retaining dentures which increases patient's confidence level. This article describes a case report in which a partially edentulous patient was successfully rehabilitated with comprehensive treatment of maxillary natural teeth supported overdenture with locator attachment (Zest Anchors) and mandibular partial denture.

\section{CASE REPORT}

A 62-year-old female patient residing at Panvel, reported to the Department of Prosthodontics of MGM Dental College and Hospital with the chief complaint of missing teeth and difficulty to masticate the food. Past medical history was not contributory. Patient had no habits. Patient gave history of earlier dental treatment for upper and lower missing teeth with fixed restorations 6 years back. However, she explained the loss of the bridges in both upper and lower left quadrant 2 years back.

On extraoral examination, patient had an ovoid facial form with straight facial profile, average facial features. Patient had short length of lips and was having a high smile line (Fig. 1). Patient did not complain of any pain, tenderness, clicking associated with temporomandibular joint.

Intraoral examination revealed a long span fixed partial denture on maxillary right side with 13 and 17 as abutments with 12,14 to 16 as pontics. On examination 23 was previously prepared tooth. In mandibular arch porcelain facing full metal crowns were present on 32, 33,41 and bridge on 42 to 45 with 42 and 45 as abutments and 43,44 as pontics (Fig. 2). Both upper and lower fixed partial dentures fabricated were not in proper occlusal plane due to which patient complained of pain and difficulty while chewing. The vertical dimension of occlusion was decreased and bite was collapsed due to loss of posterior teeth. 


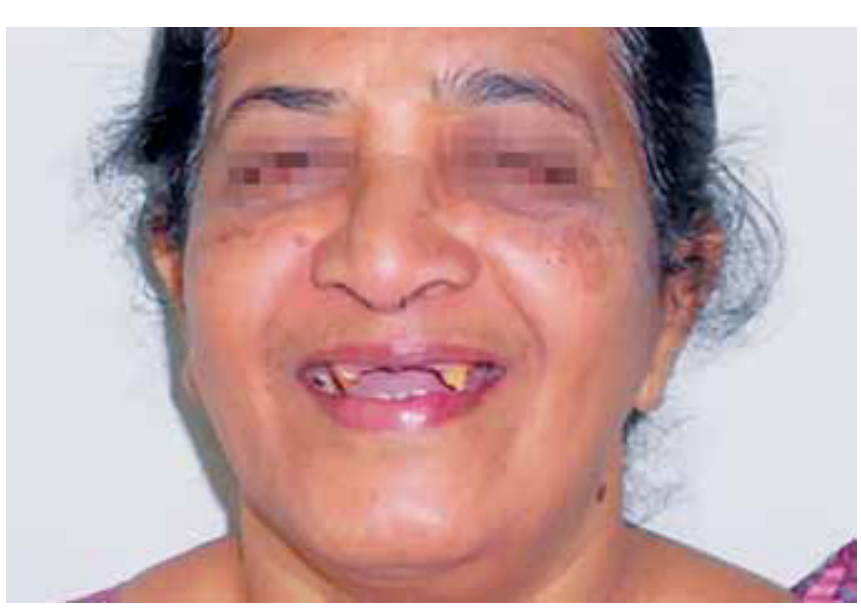

Fig. 1: Preoperative extraoral view

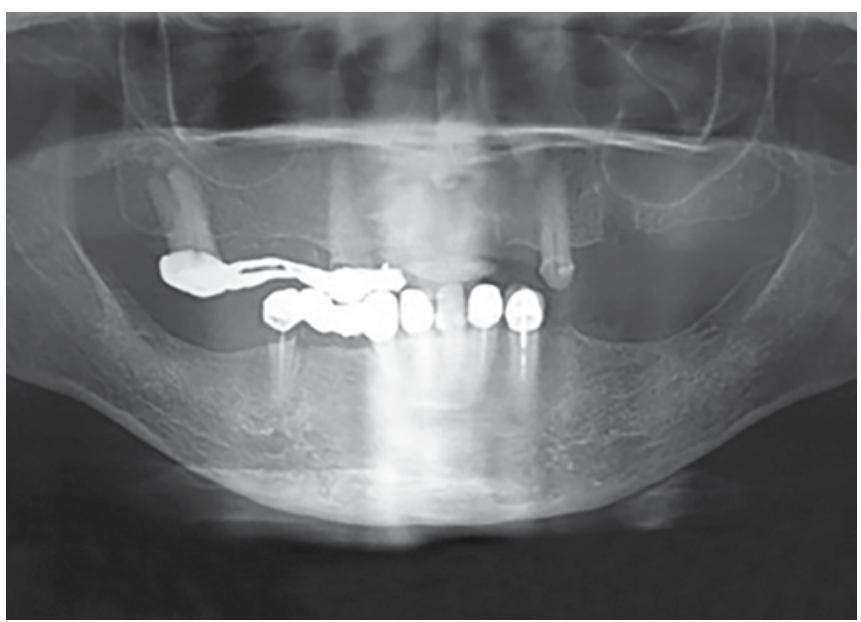

Fig. 3: Preoperative panoramic view

Radiographic examination revealed 32, 33 and 45 were root canal treated and caries were seen in 45 below the restoration (Fig. 3).

Patient was diagnosed having partially edentulous condition with restorations which needed to be replaced. The diagnostic impressions were made and casts were mounted with a tentative jaw relation to enable planning the final treatment.

\section{TREATMENT PLAN}

The fixed partial restorations and crowns were removed from both upper and lower arches (Figs 4 and 5). It revealed that 45 was grossly carious and unrestorable, so it was extracted. Diagnostic jaw relations were recorded and diagnostic try in was done.

After diagnostic try in, various treatment options like implant supported fixed partial denture for both the arches, overdenture in maxillary arch, a partial denture to replace missing teeth in mandibular arch were discussed with patient. Patient refused the treatment plan of implant supported prosthesis due to financial reasons and decided to go ahead with comprehensive treatment plan of maxillary natural teeth supported overdenture

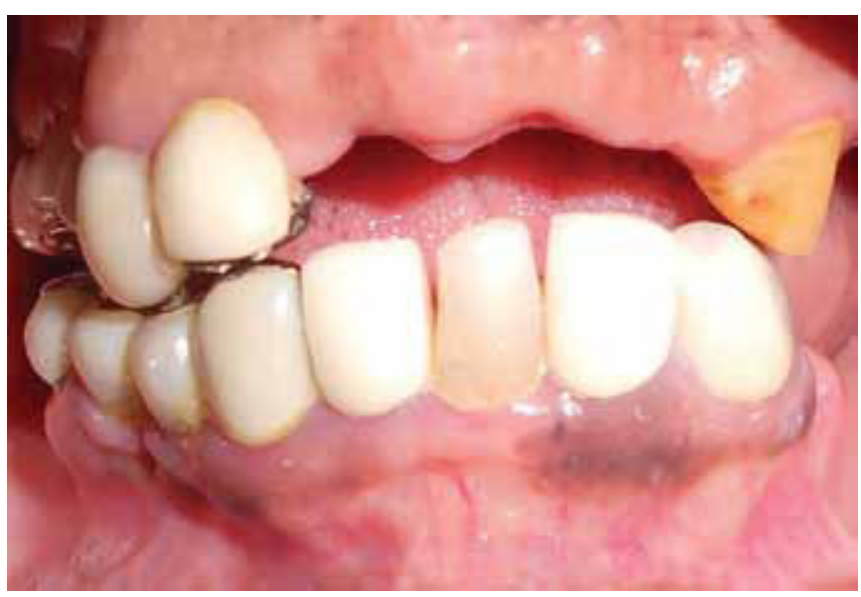

Fig. 2: Preoperative intraoral view

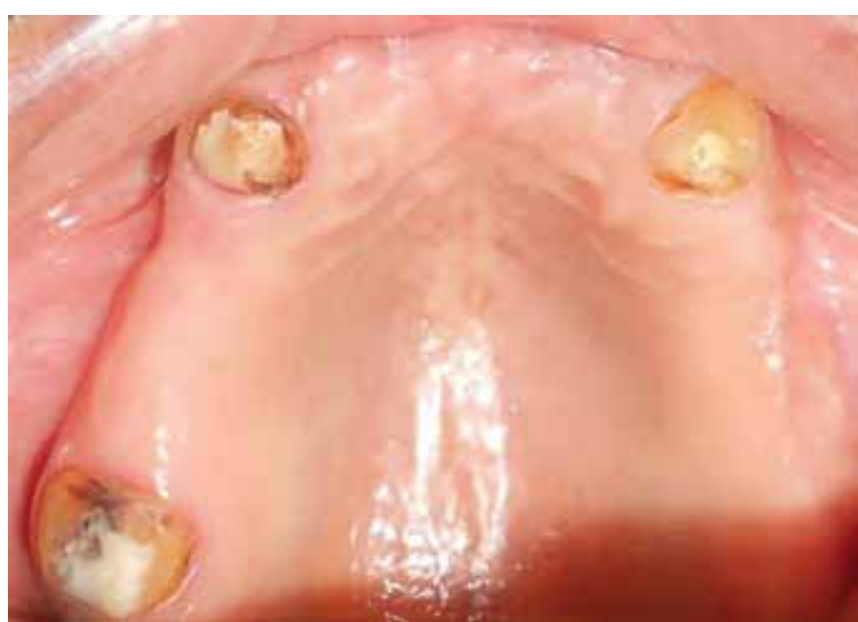

Fig. 4: Maxillary intraoral view after removal of faulty prosthesis

with locator attachment in 13,23 and amalgam plug in 17. In mandibular arch porcelain fused to metal crowns on 31 to $33,41,42$ were planned with acrylic partial denture to replace mandibular missing teeth, which would be later replaced with a cast partial denture.

\section{PROCEDURE}

Root canal treatment of $13,17,23,41$ and 42 were done. Decoronation of 13, 23 and 27 was done maintaining $1 \mathrm{~mm}$ of tooth structure supragingivally. Post space preparation was started with the pilot drill available in the Locator kit (Fig. 6). After preparation with the pilot drill, the countersink diamond bur was used. The preparation with the countersink diamond bur was only limited to prepare a very shallow recessed seat on the root surface in which female part of the attachment seats. After finishing the preparation in 13, paralleling post was placed in the prepared post space of 13. Parallelism was maintained between both the preparations by using these paralleling posts which were available in the kit (Fig. 7). After finishing the preparation with both 13 and 23, the teeth were cleaned with $0.2 \%$ chlorhexidine Gluconate (Hexidine, ICPA 


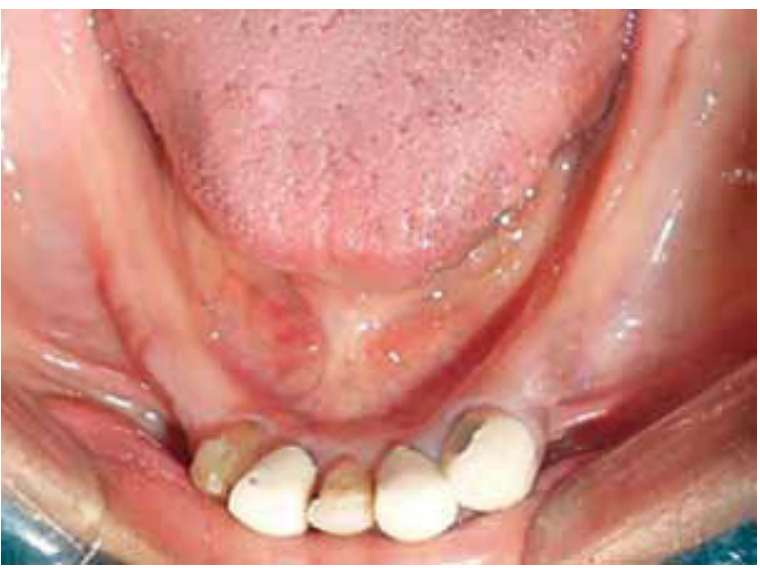

Fig. 5: Mandibular preoperative intraoral view after removal of faulty prosthesis

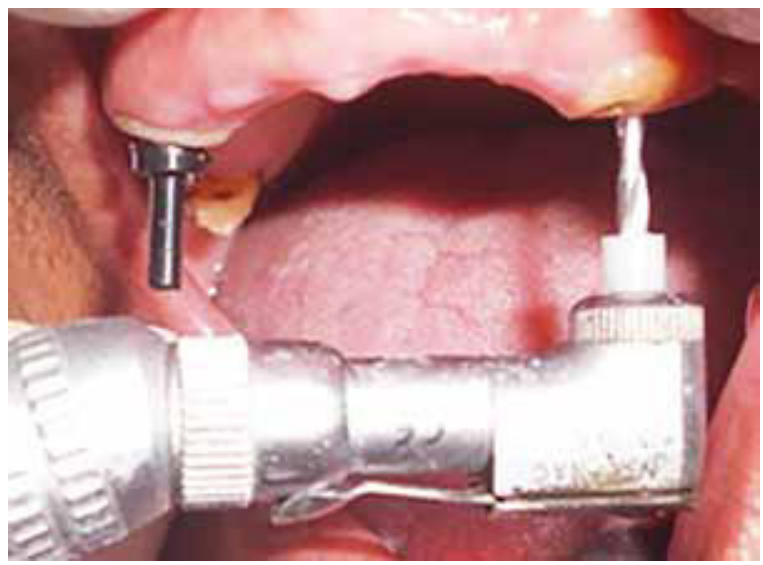

Fig. 7: Post-space preparation

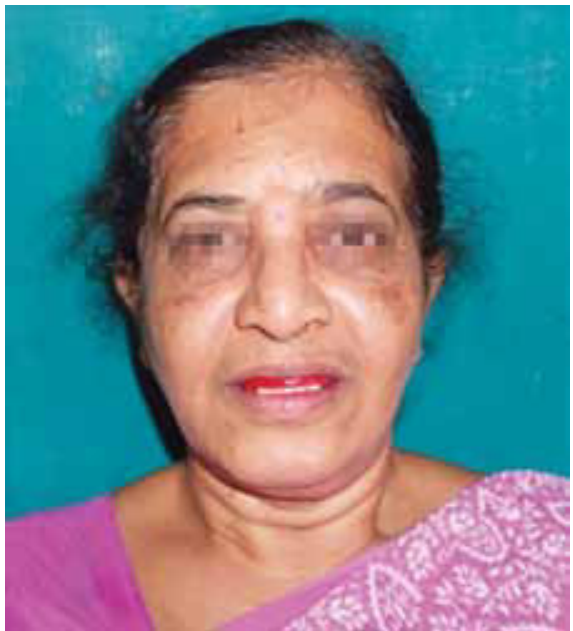

Fig. 9: Jaw relation

Health Products Ltd). The locator attachments were then cemented with dual cure resin cement (RelyX U200, 3M ESPE). While cementation, paralleling pin were used as a handle for cementing the locator attachment into the completed preparation. Amalgam plug was given in root canal treated 17. After the cement and amalgam had set completely, final contouring of the remaining tooth structure was done in all three abutments (Fig. 8). In mandibular arch crown preparation was done with

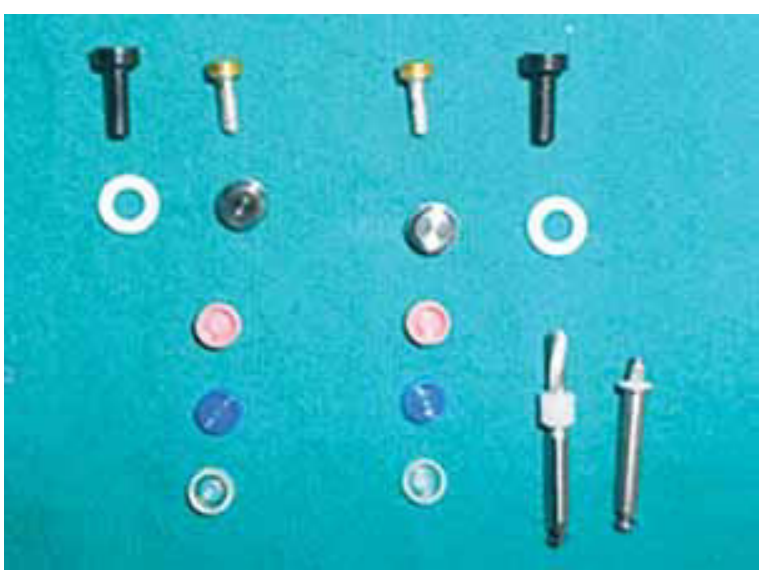

Fig. 6: Locator attachments with the drills

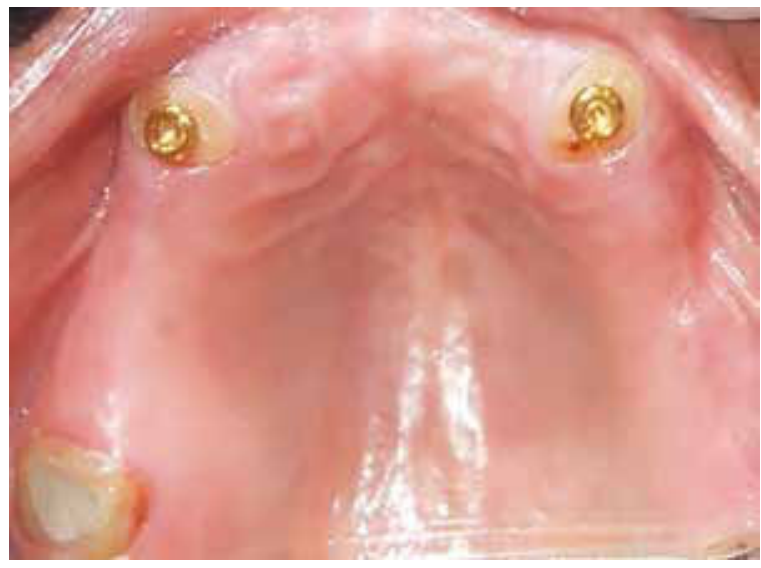

Fig. 8: Female components cemented

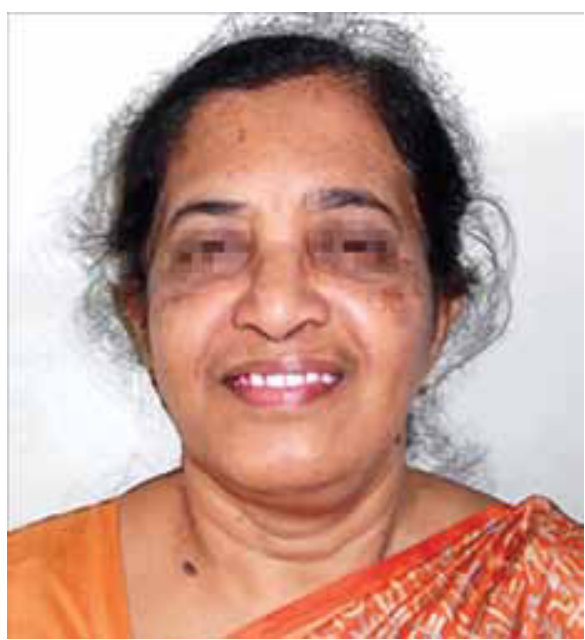

Fig. 10: Try in of waxed up dentures

31 to $33,41,42$, final impression was made and porcelain fused to metal crowns were fabricated and cemented with zinc phosphate cement (ZinCem, Medicept Dental). On the next appointment conventional impression procedure was followed for making primary impression of both maxillary and mandibular arches. Final impressions were made with special trays. Border molding was done with low fusing impression compound and final impression was made with medium bodied polyether (Impregum 
Soft, 3M ESPE). While making maxillary final impression the male part of attachments were placed on the cemented female attachments in both 13 and 23, so that space will be maintained in the denture to pick up the male parts in the denture after fabrication. Jaw relations were recorded (Fig. 9), try in was done (Fig. 10) and denture was fabricated in heat cure acrylic resin (DPI Heat cure, Mumbai). Both maxillary and mandibular dentures were inserted and recall was done after 24 hours.

One week post-insertion, when patient was comfortable with both the dentures, space was created in the maxillary denture in 13 and 23 regions, with acrylic trimmer to pick up the locator male assemblies in the denture. Locator male assemblies with black processing caps were placed into cemented females in 13 and 23 (Fig. 11). These processing caps set up the vertical resiliency needed for the final male assembly. It was verified that the denture is seating perfectly on the maxillary tissue surface without any interferences due to the locator attachments in 13 and 23. White processing sleeves were placed on the attachment which prevented blocking of the attachment with auto-polymerizing acrylic resin while picking up the attachments. Auto-polymerizing acrylic resin (DPI- Repair Resin, Mumbai) was mixed with the

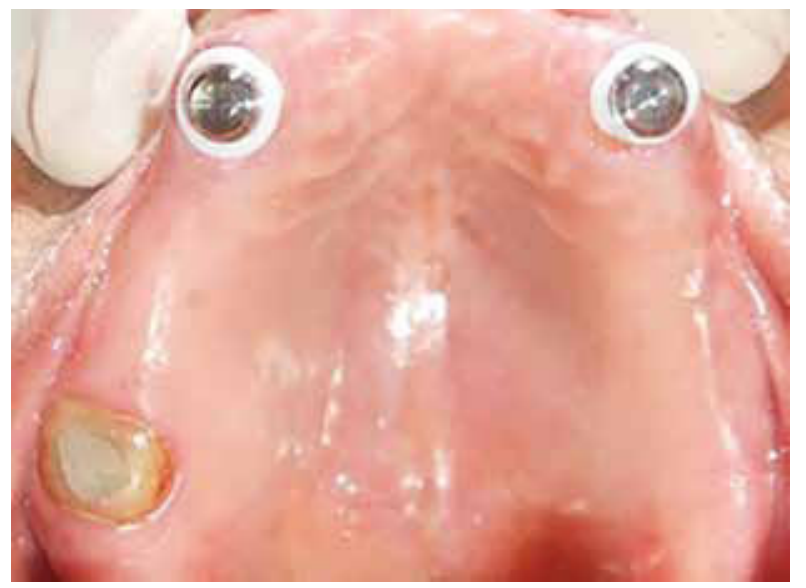

Fig. 11: Preparation for pick up of the attachment in the denture

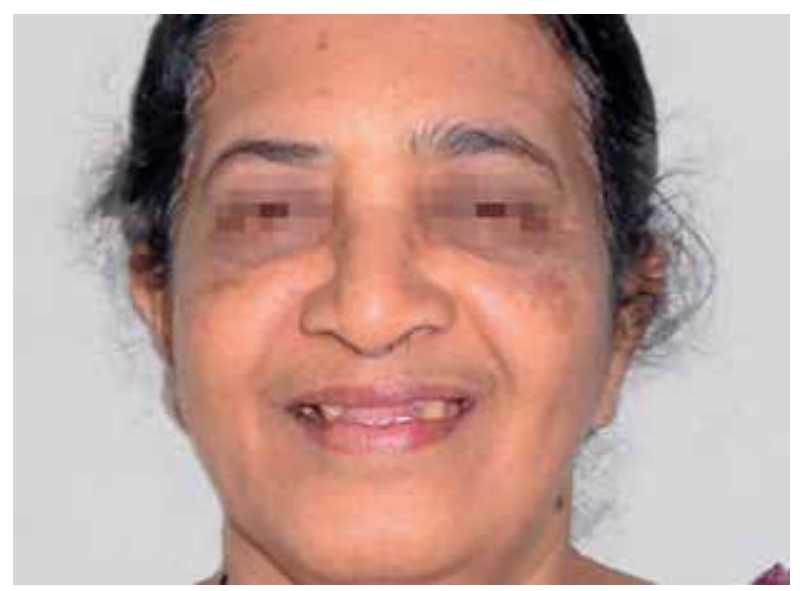

Fig. 13: Preoperative photograph monomer and placed in the denture base in 13 and 23 regions in dough stage, and the denture was placed in mouth and patient was instructed to close the teeth in centric occlusion. Minimum acrylic resin was used to prevent the excess flow of resin on intaglio surface of the denture. Once the acrylic resin was completely set, excess acrylic was trimmed off. After finishing and polishing of the denture it was placed in patient's mouth to evaluate the complete sitting of the denture and occlusion. The black processing cap was replaced with white retentive cap (Fig. 12). Denture insertion was done (Figs 13 and 14). Instructions were given to the patient about placement and removal of the overdenture, hygiene maintenance and periodic visits for professional cleanings and attachment evaluation.

\section{DISCUSSION}

Many of the patients who have complete dentures are dissatisfied with the limited retention and stability of their dentures. They always have fear of loosening of the denture while talking and eating. Resorption of the alveolar ridges, decline in the patient's neuromuscular function, decrease in proprioceptive response resulting from the loss of teeth, eventually leads to failure of

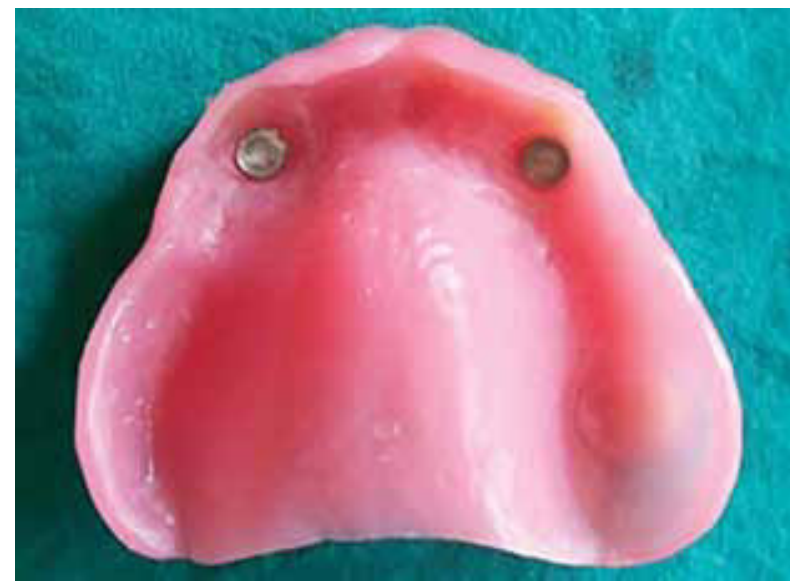

Fig. 12: Attachments picked up in the denture

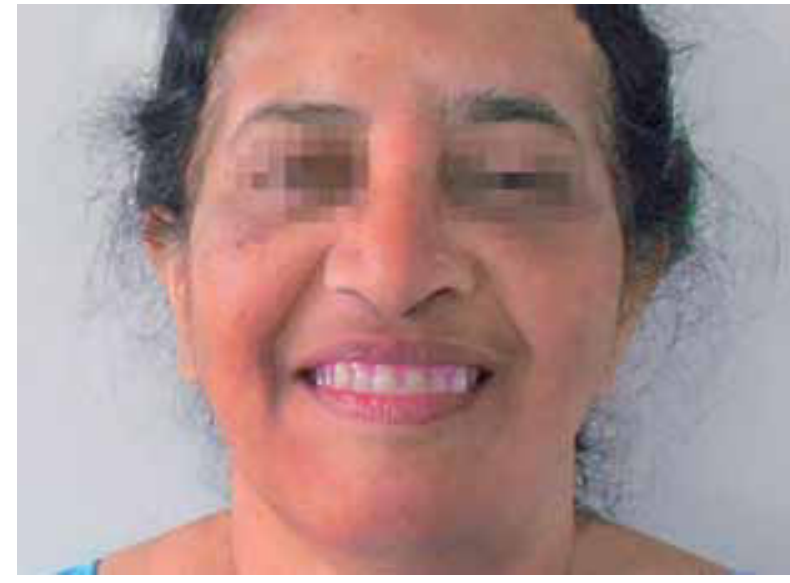

Fig. 14: Postoperative photograph 
dentures. These problems can be overcome with the help of overdentures. It provides better function than conventional tissue supported complete denture through a variety of parameters such as improved masticatory efficiency, preservation of proprioceptive response, better retention, stability, support and less trauma to supporting tissues. Alveolar bone resorbs at a faster rate without the support of natural teeth. But in case of overdentures, retained teeth will maintain the alveolar bone support and also prevent the rapid bone loss. ${ }^{4}$ Rissin and House ${ }^{5}$ analyzed the masticatory performance of three dental patient groups- those with natural dentition, those wearing complete dentures, and those wearing overdentures. Food was chewed by each patient, then passed through a No. 12 sieve. The chewing efficiency of patients with natural dentition was measured at $90 \%$, complete denture wearers $59 \%$, and patients with overdentures $79 \%$. Chewing efficiency with a rootsupported overdenture was 34\% higher in patients who previously wore a complete denture. This increase in function, retention, and stability leads to better health and phonetics in denture wearers. These factors also elevate patients' self-esteem and increase their confidence level. In this case patient desired the dentures which will serve her main requirement of mastication. She wanted her denture to be well retained without loosening while speaking and chewing and she also wanted to save her remaining natural teeth. Natural tooth supported overdentures fulfills the requirements of the patient.

Root-supported overdentures gain their retention and stability from the use of attachments. There are mainly three types of overdenture attachment designs: bar type, supraradicular type, and intraradicular type. The bar type spans an edentulous area and connects two or more teeth with rigid fixation. Supraradicular type attachments are placed on top of the existing root structure. Intraradicular attachments are placed within the endodontically treated root structure of natural teeth. All three designs can be used in the construction of maxillary and mandibular overdentures. ${ }^{6,7}$ But overdentures require careful assessment of vertical space. There must be sufficient room for the possible attachments, together with an adequate thickness of denture base material and artificial teeth, all this without jeopardizing the strength of the denture. ${ }^{8}$ Locator attachment (Zest Anchors) requires least vertical space with a total attachment height of $3.17 \mathrm{~mm}$ which is least among available attachments for natural teeth. The pivoting locator male allows a resilient connection for the prosthesis. The retentive nylon male remains completely in contact with the female socket while its metal denture cap has a full range of rotational movement over the male. The unique dual retention provides the locator attachment with a greater retention surface area than other attachments. Locator attachment creates a longer lasting, more retentive attachment for natural teeth supported overdentures. The supraradicular design includes a choice of a straight post or two angled posts (10 and 20 degrees) to accommodate divergent roots. Locator male attachments are available in varying amounts of retention. The black male attachment provides the least amount of retention at 1.0 pound: the pink male attachment provides 3.0 pounds of retention; and the white male attachment provides 5.0 pounds of retention and is considered the regular or standard for this system. With two to four abutment teeth, the maximum retention should be used (the white male at 5.0 pounds per attachment). In this case, in diagnostic jaw relation it was observed that the available vertical space for attachment is minimal. Locator attachment fulfills all the requirements.

\section{CONCLUSION}

A comprehensive treatment was planned for the patient. Replacing crowns to achieve the proper occlusal plane was important. Maintaining few teeth in the maxillary arch enabled the fabrication of the overdenture with locator, this enhanced the retention of the dentures with long-term preservation of the edentulous ridges keeping in mind the patients interest.

\section{REFERENCES}

1. Preiskel HW. Overdentures made easy: a guide to implant and root supported prostheses, Chicago: Quintessence Publishing Co Inc; 1995.

2. Ledger E. On preparing mouth for the reception of a full set of artificial teeth. Br J Dent Sci 1856;1:90.

3. Winkler S. Essentials of complete denture prosthodontics. 2nd ed. New Delhi: AITBS Publishers; 2009.

4. Terracciano-Mortilla L. Prosthodontics and maintenance for dental auxiliaries. Implant News Views 2000;2-4.

5. Rissin L, House JE, Manly RS, Kapur KK. Clinical comparison of masticatory performance and electromyographic activity of patients with complete dentures, overdentures and natural teeth. J Prosthet Dent 1978 May;39(5):508-511.

6. Morrow RM. Handbook of immediate overdentures. St. Louis: Mosby; 1978. p. 48.

7. Delsen testing laboratories, Inc. Insertion and extraction test of retention loss: Test Report 3-30-2000; 1-7.

8. Schneider AL. Restoring implants with an overdenture using the locator implant attachment from Zest Anchors, Inc. Dent Today 2000:41. 